\title{
Species of Coagulase- Negative Staphylococci Isolated from Anterior Nare and Milk of Ruminant Animals and Contacts Persons in Maiduguri, Nigeria
}

\author{
Mai-Siyama Bukar Ibrahim ${ }^{1}$, Okon Kenneth Okwong ${ }^{2}$, Adamu Nuhu Bala ${ }^{1}$, \\ Mohammed Abdulrahman', Hamidu Ibrahim ${ }^{3}$, Hambali Idris Umar', Jajere Saleh Mohammed ${ }^{1}$ \\ ${ }^{1}$ Department of Veterinary Public Health, University of Maiduguri, Maiduguri, Nigeria \\ ${ }^{2}$ Department of Medical Microbiology, Federal Medical Centre, Makurdi, Nigeria \\ ${ }^{3}$ Department of Immunology and Infectious diseases, University of Maiduguri Teaching Hospital, Maiduguri, Nigeria
}

Email address:

drbukar@gmail.com (Mai-siyama I. B.), okonkenneth@gmail.com (Okon K. O.), nuhubala2@gmail.com (Adamu N. B.), abduldvm@gmail.com (Mohammed A.), hamiduwarabe@gmail.com (Hamidu I.),idrisumarhambali@yahoo.com (Hambali I. U.), drmsalehjajere@gmail.com (Jajere S. M.)

\section{To cite this article:}

Mai-Siyama Bukar Ibrahim, Okon Kenneth Okwong, Adamu Nuhu Bala, Mohammed Abdulrahman, Hamidu Ibrahim, Hambali Idris Umar, Jajere Saleh Mohammed. Species of Coagulase- Negative Staphylococci Isolated from Anterior Nare and Milk of Ruminant Animals and Contacts Persons in Maiduguri, Nigeria. Animal and Veterinary Sciences. Vol. 3, No. 5, 2015, pp. 128-131. doi: 10.11648/j.avs.20150305.11

\begin{abstract}
Coagulase negative staphylococci (CNS) are primary cause of mastitis in ruminant animal, and can either be transmitted by contagious or by environmental means. Therefore, we speculate whether there are similarity in the species distribution of CNS colonsing the anterior nare and milk of ruminant animals that can serve as source of infection. The study examined the species of CNS from the anterior nare of ruminant animals and contact persons. A total of 75 CNS isolates were analysed using matrix-assisted laser desorption ionization-time of flight mass spectrometry (MALDI-TOF MS), mecA gene detection by PCR assay and antibiotic susceptibility testing according to CSLI guidelines. Overall, four CNS spp were identified, S.sciuri predominate $71(96 \%)$ and were recovered from all samples analysed, while one specie each (1.3\%) of S.lentus, S.condementii and S.xylosus (1.3\%) respectively. No mecA gene was detected in the CNS spp identified. The CNS spp demonstrated low to moderate resistance pattern (15-30\%) to all antibiotics tested. In conclusion, the study provided a baseline epidemiological information on CNS spp colonizing the ruminants ruminant animal and contact persons. In addition, non-detection of mecA gene and high sensitivity pattern demonstrated by the CNS species.
\end{abstract}

Keywords: Coagulase Negative Staphylococci, Species, Ruminant Animals, Maiduguri

\section{Introduction}

Coagulase negative staphylococci (CNS) are emerging as pathogenic agents in both human and veterinary field. It is seen as the reservoir and responsible for horizontal transmission of methicillin resistance genes to susceptible staphylococci resulting in MRSA and MRCNS[ 7 ]. CNS, is the major causative agent of mastitis in ruminant animals resulting in significant economic losses to livestock farmer[5,13]. Wide variety of CNS species responsible for mastitis includes S.chromogenes and S.epidermidis that are more adaptive to the mammary gland, while others like S. equorum, S.sciuri, S.fleuretti, S.cohnni, S.devriesei, S.xylosus,
S.arlettae and S.succinc are known to have environmental transmission pattern[2,7,11].

In Nigeria, S.aureus is the most common of the gram-positive bacteria isolated in both human and veterinary laboratories. The CNS identification is seldom carried out probably due to the lack of basic facilities and research materials. However, molecular techniques like MALDI-TOF, offers a fast, accurate and species specific identification [6] but not applicable in resource limited laboratories.

In the northeastern Nigeria, epidemiological information gap exist on the species of CNS colonizing ruminant animals. Therefore, this is the first report to examine the species of CNS from the anterior nare of ruminant animals and contact persons. The goals of the study, was to address some salient 
epidemiological questions, (i) whether there are similarity in the nasal CNS spp of ruminant animals and those isolated from mastitis cases in some published works (ii) the presence of mecA gene among the CNS isolates and (iii) the determine the degree of antibiotic resistance among the CNS spp.

\section{Methodology}

\subsection{Samples/Isolates Collection}

Nasal swabs of ruminant animals and contact person were collected at the Maiduguri Metropolitan council between January and June 2012. The University of Maiduguri, Faculty of Veterinary Medicine institutional review board approved the study and Borno state Veterinary department authorized the specimens collections. As documented in previous published work [9] a total of 510 nasal swabs and milk samples were collected from 12 ruminant animals breed and contact persons, 87(17.1) and 75(14.7\%) were identified as S.aureus and CoNS isolated respectively.

\subsection{CNS Species Identification and Antimicrobial Susceptibility Testing}

The CNS species -specific test was performed by MALDI-TOF as previously described[6], and the analysis was carried out at the institute of medical microbiology, University Hospital Muenster, Germany. The mec A gene detection was carried out by PCR assay [15]. Antibiotic susceptibility pattern was carried out according CSLI guidelines [3] on Mueller-Hinton Agar. The following antibiotics were tested, penicillin, ampicillin, gentamycin, tetracycline, erythromycin, cotrimoxazole, ciprofloxacin, ofloxacin, and clindamycin. The antibiotic susceptibility was determined according to the agent breakpoint.

\section{Result}

Of the 75 CNS isolates analysed, (table 1), 21(28\%) were recovered from cattle, $18(24 \%)$ from camel, $7(9.3 \%)$ each from goat and sheep and one(1.3\%) from contact person. Demographic information showed that $70(93.3 \%)$ of the ruminants animals grazed extensively, while local remedies were used for the treatment of veterinary diseases $(90.7 \%)$. Majority $(n=72,96 \%)$ of the CNS isolates were identified as S.sciuri, and recovered from all the sampled analysed., with S.lentus from cattle and S.condementii and S.xylosus from goat. No methicillin resistance gene(mecA) was detected in the CoNS idenifed. Overall, all the CNS spp demonstrated high sensitivity of $100 \%$ with S.lentus, S.condementii and S.xylosus, while S.sciuri resistance percentage ranged between $15-30 \%$ to all antibiotics tested.

Table 1. Demographic and bacteriological variables of the samples analysed in Maiduguri.

\begin{tabular}{ll}
\hline Samples(n=75) & Frequency(\%) \\
\hline Cattle & $21(28)$ \\
Sheep & $7(9.3)$ \\
Goat & $21(28)$ \\
Camel & $18(24)$ \\
Milk(cattle) & $7(9.3)$ \\
Contact person & $1(1.3)$ \\
Grazing & \\
Extensive & $70(93.3)$ \\
Intensive & $5(6.7)$ \\
Medication & \\
Antibiotic usage & $7(9.3)$ \\
Local Remedy & $68(90.7)$ \\
Coagulase negative staphylococci & \\
S. sciuri & $72(96)$ \\
S.lentus & $1(1,3)$ \\
S.condementii & $1(1.3)$ \\
S.xylosus & $1(1.3)$ \\
\hline
\end{tabular}

Table 2. Distribution of CNS within the samples analysed.

\begin{tabular}{llllllll}
\hline & cattle & sheep & goat & camel & Human & Milk & Total \\
\hline S.sciuri & 20 & 7 & 19 & 18 & 7 & 1 & 72 \\
S.lentus & 1 & & 1 & & & & 1 \\
S.condementii & & & 1 & & & 1 \\
S.xylosus & 21 & 7 & 21 & 18 & 7 & 1 & 1 \\
Total & & & & & & \\
\hline
\end{tabular}

Table 3. Antibiotic resistant pattern(\%) of CNS isolates.

\begin{tabular}{lllll}
\hline & S.sciuri & S.lentus & S.condementii & S.xylosus \\
\hline Pen & 20 & - & - & - \\
amp & 30 & - & - & - \\
gen & 30 & - & - & - \\
tet & 25 & - & - & - \\
ery & 15 & - & - & - \\
sxt & 30 & - & - & - \\
cpx & - & - & - & - \\
ofx & - & - & - & - \\
cld & - & - & - & - \\
\hline
\end{tabular}

Pen-penicillin, amp-ampicillin, gen-gentamycin, tet-tetracycline, sxt-contrimoxazole, cpx-ciprofloxacin, ofx-ofloxacin,cld-clindamycin

\section{Discussion}

CNS are emerging as bacterial pathogens of public health concern in both human and medicine field. In veterinary field, it is primarily identified as the major cause of subclincal and chronic masitiis with consequential negative impacts like high 
mortality, cost of animals treatment, and economic loss. Presently, CNS are seen as the reservoir of methicillin resistance gene that can be horizontally transferred to other susceptible staphylococci[7]. This is of public health concern because it is responsible for the emergence of MRSA, livestock-associated methicillin-resistant S.aureus (LAMRSA) and methicillin-resistant coagulase negative staphylococci(MRCNS). In Maiduguri, Mai-siyami et al[9] reported MRSA nasal carriage prevalence of $34.6 \%$ among ruminant animals and contact persons. The prevalence may be considered to be relatively high, due to lack of preexisting epidemiological data for comparison and documented predisposing risk factors. Therefore, the findings of this study provides a baseline epidemiological information on the CNS colonizing the anterior nare and milks of ruminant animals and contact in the study area.

The demographic variables of the ruminant animals as documented in the study questionnaire- extensive grazing practices and the use of local remedies for the treatment of veterinary diseases affirmed the common practices among the nomadic in the northern part of Nigeria.

Overall, S.sciuri predominates the total CNS spp identified( $n=72,96 \%)$ and were recovered from all the samples analysed, while one specie each(1.3\%) of S. lentus, S.condementii and S.xylosus . In a similar study conducted in Switerzland, Huber et al[7] reported S.sciuri prevalence of $63.5 \%$, which was also recovered from all the samples analysed, while S.lentus accounted for $15.7 \%$. However, some studies have reported the recovery of S.lentus from other animals species such as horses[10], cattle sheep, and goat $[15,16]$.

To collaborate our study speculation that there are similarity between nasal carriage CNS spp and those isolated from mastitis cases. Piessens et al[11], reported that S.equorum, S.sciuri, S.heamolytius and S.fleuretti were predominant in the environment and milk samples. While studies have identified S.sciuri, S.xylosus and S.cohnii as environmental spp, which are capable of causing intramammary infection, especially in compromised animals $[4,11,12,15]$. In contrast, several studies have observed that the level of preventive measures does not necessarily translate to reduction in the prevalence of CNS infection[14,16]. But, only few studies have identified the possible reservoir of CNS infection[11]. In this study, only one specie of S.ylosus was identified, which has been identified as one of the primary reservoirs of CNS infection that can be contracted from environment, superficially from sawdust stock[11].

Methicillin resistant staphylococci (MRCNS) are emerging as a public health concern in veterinary field, .The methicillin resistance genes have been reported to evolve in coagulase negative staphylococci and transferred horizontally to susceptible staphylococci, S.sciuri and S.fleuretti are known as natural reservoir of mecA gene [7]. The first report of MRCNS was in chicken[8 ], while other studies have reported it in ruminant animals like cattle sheep and goat $[10,15]$.The high prevalence of MRCNS reported among large scale livestock in Europe and US, have consequential impact on food safety and potential spread of mecA genes to S.aureus(MRSA). In this study, no mecA genes was detected in all CNS species identified. Similarly, high sensitivity pattern was demonstrated by the CNS spp tested. The reason for such findings may be due to low level of antibiotic usage compared to high usage of local remedies as documented in the study. In Europe and US, high prevalence of MRCNS and antibiotic resistance in CNS isolates have been reported[7 ], that may be attributable to indiscriminate antimicrobial incorporation in animal feeds and also as growth promoter

Though this study has provided a baseline epidemiological information, nevertheless there are limitations in the study, (I) number of CNS isolates analysed were relatively few (ii) non data on CNS spp from mastitis cases for comparison.

In conclusion, this study findings has provided a baseline epidemiological information on nasal carriage CNS spp among ruminant animals and contact persons. In addition, it revealed predominance of S.sciuri, non-detection of mecA gene and high sensitivity pattern. However, further studies are needed to evaluate the environmental effect on the distribution of CNS species.

\section{Acknowledgement}

We acknowledge the support and assistance of the staff of Institute of Medical Microbiology, University Hospital, Muenster in the analysis of the CNS spp, and the grant for laboratory attachment to one of the authors $(\mathrm{OKO})$.

\section{References}

[1] Bajogi FA, Moodley A, Baptista KE, Jense VF, Guardabassi L. "Occurrence speceies, distribution, antimicrobial resistance and clonality of methicillin and erythromycin-resistant staphylococci in the nasal cavity of domestic animals". Vet Microbiol, 121, 307-315, 2007.

[2] Bansal BK, Gupta HK, Shafi TA, Sharma S. "Comparative antibiogram of coagulase negative staphylococci(CNS) associated with subclinical and clinical mastitis in dairy cow.Vet World, 3, 421-425.2015

[3] CSLI."Perfomance standard for antimicrobial Disk susceptibility Test.Sixteeth International Supplement Clinical and Laboratory Standard Institute”, Wayne, PA,USA, 2006

[4] Davidson TJ, Dohoo IR, Donald AW Hariharan H, Collins K, "'A cohort study of coagulase negative staphylococcal mastitis in selected dairy herds in Prince Edward Island.”. Can,J,Vet Res.56,275-280. 1992

[5] Denis M, Lacy-Hulbert SJ, Buddle BM, WilliansonJH, Wedlock DN,"Streptococcus uberis-specific-T- cells are present in mammary gland secretion of cow and can be associated to kill S.ubertis. Vet Res Community, 35, 145-150, 2011

[6] Dubois D, Leyssene D, Chacomac JP, Rostrzewa M,Schmit PO, Talon R, Bonnet R,Dalmas J.'Idenification of a variety of staphylococcal species by matrix assosciated desorption ionization- time of flight mass spectrometry". J.Clin Microbiol. 48,941-945, 2010 
[7] Huber H, Ziegler D, Pfluger V, Vogel G V, Zwelfe C, Stephen R. 'Prevalence and characterisitic of methicillin-resistant coagulase-negative staphylococci from livestock, chicken, carcasses, milk, tank milk, minced meat and contact persons.”.BMC Veterinay Research, 79; 2011.

[8] Karmano J,Shimizu A, Saitoh Y, Yagi M, Saito T, Okamato R."Isolation of methicillin-resistant coagulase negative staphylococci from chicken".J.Clin Micribiol.34; 2072-2077, 1996.

[9] Mai-siyama IB, Okon KO,Adamu NB, Askira UM, Isyaka TM, Adamu SG, Mohammed A. "' Methicllin-resistant Staphylococcus Aureus (MRSA) colonization rate among ruminant animals slaughtered for human consumption and contact persons in Maiduguri, Nigeria" AJMR, 8(27),2643-2649, 2014

[10] Moodley A, Guarddbassi L, 'Clonal spread of coagulase negative staphylococci among horses, personnel, and environmental sites of equnine facilities". Vet Microbiol.137,397-401, 2009

[11] Piesseens V, Van Coillie, Verbist B, Supre K, Braem G, van Nuffel A, De Vuyst L, Heyndridex De Vlieghert S. "'
Distribution of coagulase-negative staphylococci species from milk and environment of dairy cow differs between herds." J.Dairy Sci.94, 2933-2944, 2011

[12] Supre K, Haesebronck F, Zadoks,RN Vaneechvutta M, Pieperss V, De Vliegher S." Some CNS species are affecting udder health more than others".J.Dairy Sci.94, 2329-2340.

[13] Taponen S, Bjorroth J Pyorala S"Coagulase negative staphylococci isolated from bovine extra mammary site and intramammary infection in a single herd.J.Dairy Res.75, 422-429, 2008

[14] Thorberg BM, Danielssom-Tham ML, Emmanuelson U, Walker KP"Bovine subclinical mastitis caused by different type of coagulase negative staphylococci.J.Dairy Sci."92, 4962-4970, 2009.

[15] Thorberg BM, Kuhn I, Aarestrup FM, Brandstrom B, Jonsson P, Danielsson-Tharm. 'Pheno and genotyping of Staphylococcus epidermidis isolated from bovine milk and human skin" Vet Microbiol, 115, 163-172, 2006

[16] Zhang Y, Agidi S, LeJenune JT.”Diversity of staphylococcal cassette chromosome in coagulase negative staphylococci of animal origin." Appl.Microbiol,107, 1375-1383,2009. 